\title{
Early signs of the glaucomatous disc
}

\section{J. PRIMROSE}

\section{London}

In a survey of new glaucoma clinic patients over 40 years of age, which was carried out in $\vec{P}$ I 968 and was based on the appearance of the optic disc (Primrose, 1969), it early became्山 clear to me that the peripapillary halo or ring, commonly considered to be more a senile than a glaucomatous condition, was in fact more than twice as likely to be associatec.6. with chronic simple glaucoma as not (Table) and that it occurred at an early stage of the disease.

Table Glaucoma simplex and peripapillary atrophy

\begin{tabular}{|c|c|c|c|c|}
\hline \multicolumn{4}{|c|}{ New attendances in 1968} & 3,072 \\
\hline \multicolumn{4}{|c|}{ Cases selected for analysis on basis of appearance of disc } & 69 \\
\hline Glaucoma & $\left\{\begin{array}{l}\text { Typica } \\
\text { Some j } \\
\text { Cuppir }\end{array}\right.$ & $\begin{array}{l}\text { al halo glaucomatosus } \\
\text { juxtapapillary atrophy } \\
\text { ng without juxtapapillary signs }\end{array}$ & $\left.\begin{array}{r}28 \\
21 \\
3\end{array}\right\}$ & $5^{2}$ \\
\hline Peripapillar & ry halo & $\left\{\begin{array}{l}\text { Glaucoma } \\
\text { No glaucoma } \\
\text { Glaucoma suspects }\end{array}\right.$ & $\left.\begin{array}{r}28 \\
10 \\
5\end{array}\right\}$ & 43 \\
\hline
\end{tabular}

Some second eyes, which were still free of cupping, showed a halo similar to that seers $\overrightarrow{\vec{p}}$ in the first eyes. Only four of 28 cases of glaucoma with typical peripapillary haloes could be considered advanced. More than half the new cases of glaucoma showed ap. typical halo (Fig. I, opposite), and this proportion excluded cases of chronic narrow-angle. glaucoma in which the halo also occurs and cases of myopic peripapillary atrophy in which a susceptibility of the disc to the insidious development of cupping is already accepted.

Most of the remainder of the cases of glaucoma simplex showed a small amount ob juxtapapillary choroidal atrophy, and only three out of $5^{2}$ cases (i.e. 6 per cent.) showed no juxtapapillary signs. This is seen as a slight recession of the choroid away from the edge of the disc; it may be present only around one sector of the disc or may extend al $b$ round it as a narrow ring (Fig. 2, opposite, and Fig. 3, overleaf). This narrow zone of atrophy merges with the edge of the disc, but one can see that there is a thickness to the edge between the angulation of the vessels and the normal retina and choroid. I have been unable to find a specific description of this edging in the literature though manyw photographs and some paintings show it well (e.g. Fig. 55 I : Ballantyne and Michaelson $\widetilde{F}$ I962).

These juxtapapillary signs, whether as a sector, a narrow ring, or a typical halo, are্ thought to arise from insufficiency in the zone of supply of one or more of the two or three 
short ciliary arteries which form, or fail to form, the circle of Zinn. The peripapillary choroid and prelaminar tissue of the disc is subject to the intraocular pressure, and because there are branches to the pial plexus the blood can take that alternative path when there

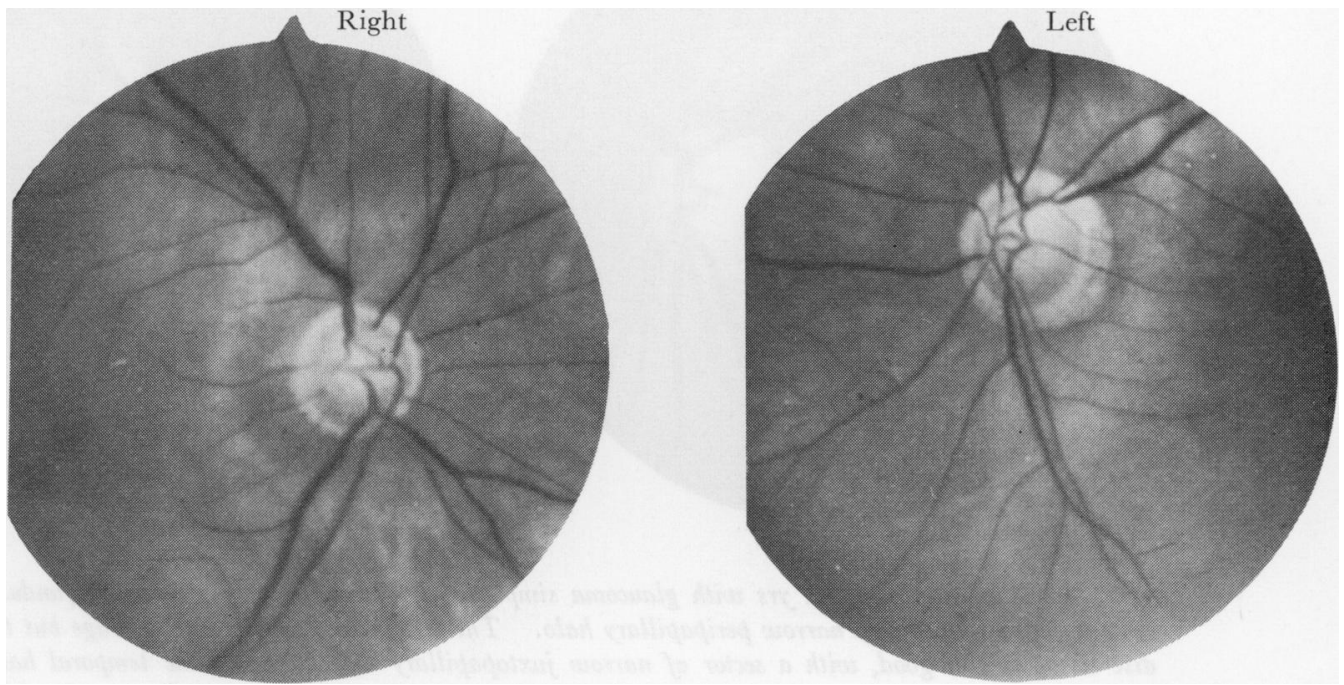

F I G. I A woman aged 65 yrs in May, 1968. Right and left fundus photographs, showing typical peripapillary haloes. Right cup reaches edge of disc in upper temporal quadrant only. Early inferior arcuate scotoma and enlarged blind spot. Left cupping and pallor of upper half of disc. Considerable inferior field loss and enlarged blind spot. Intraocular pressure at first attendance: $44 \mathrm{~mm} . \mathrm{Hg}$ (Schiötz) in the right eye and $47 \mathrm{~mm} . \mathrm{Hg}$ in the left

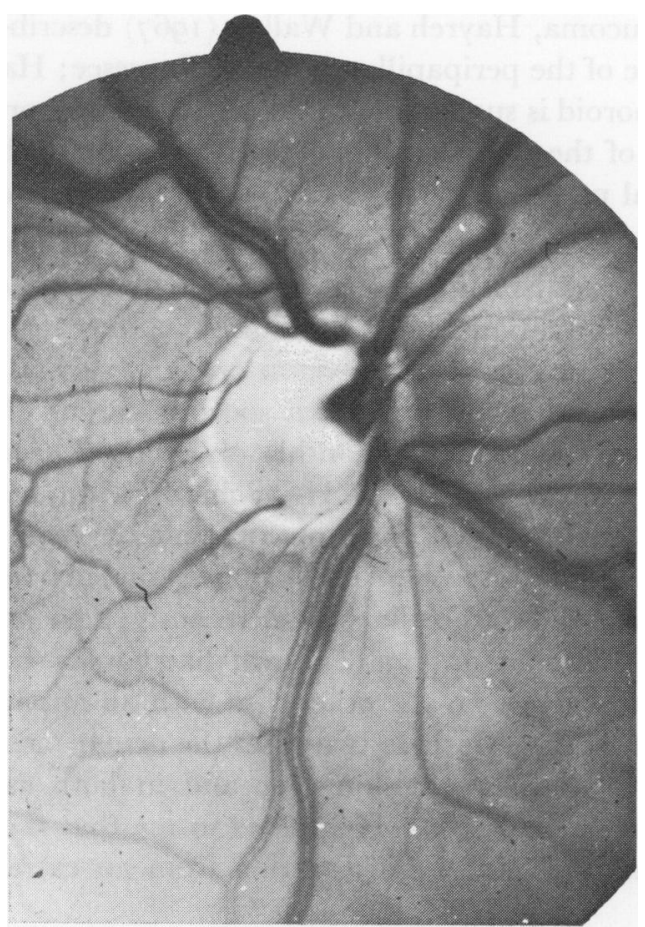

FIG. 2. A man aged 64 yrs. The right fundus shows typical glaucomatous cupping, with vessels displaced to nasal side with angulation over edge of disc. Narrow juxtapapillary choroidal atrophy is present, probably all the way round, though most marked in inferior temporal section. Veins mildly congested. Marked inferior field loss. Intraocular pressure $42 \mathrm{~mm} . \mathrm{Hg}$ (Schiötz) both eyes (Primrose, 1969) 


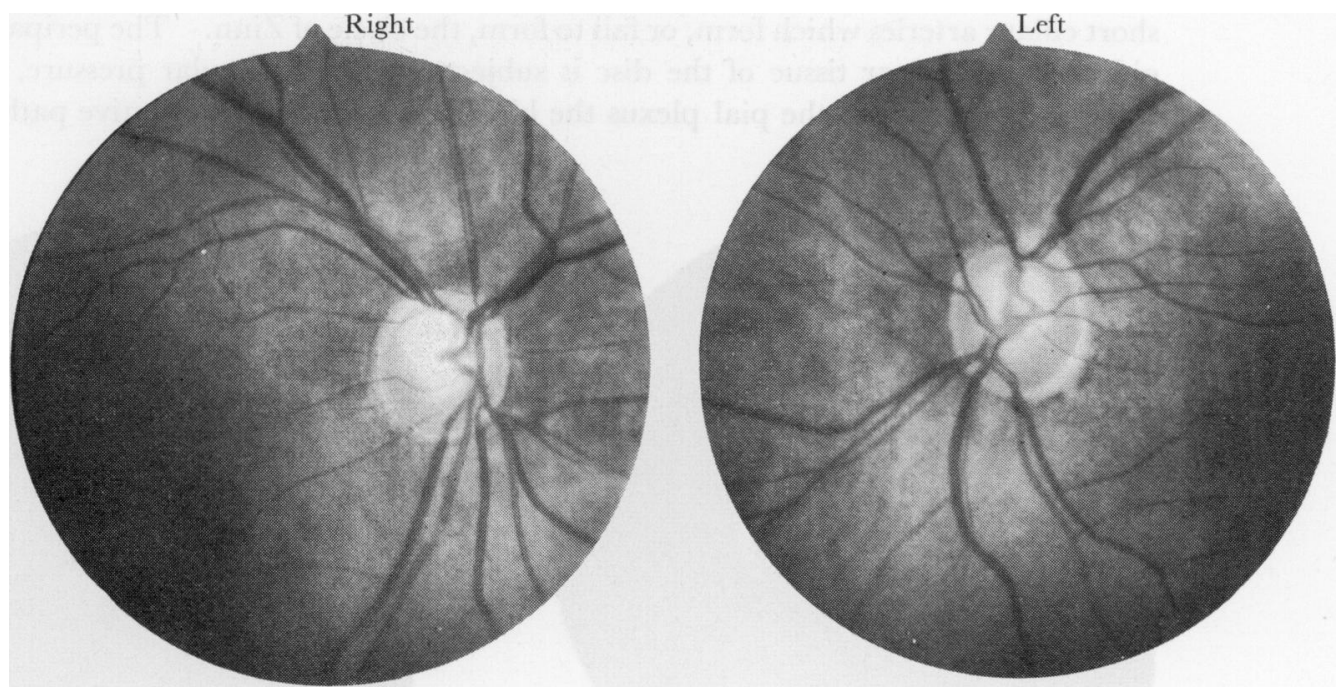

FIG. $3 A$ woman aged 62 yrs with glaucoma simplex. In January, 1970, the right fundus shows glaucomatous cupping with very narrow peripapillary halo. The left shows a sharp inferior edge but the colour of the disc tissue is still good, with a sector of narrow juxtapapillary atrophy round the temporal half. The intraocular pressure at the first attendance was $40 \mathrm{~mm} . \mathrm{Hg}$ (Schiötz) in both eyes. During the following year an increase in cupping occurred

is increased pressure on these tissues, an alternative which is denied to the retinal artery system and the other posterior ciliary arteries (Gafner and Goldmann, 1955). Of several reports on fluorescein studies in glaucoma, Hayreh and Walker (1967) describe the general faintness of the disc and the failure of the peripapillary halo to fluoresce; Hayreh (1969) has shown that the peripapillary choroid is susceptible to raised intraocular pressure in the same way as the prelaminar tissue of the disc; and Boyd and Rosen (1970) have demonstrated a circumpapillary choroidal perfusion delay in cases of chronic glaucoma.

Sector haemorrhage at the edge of a glaucomatous disc has recently been described by Drance and Begg (1970). A perusal of the case notes made at the time of the first visit of the patients included in the 1968 survey, showed that three of the cases of glaucoma simplex had been recorded as having tiny haemorrhages on one disc such as Drance and Begg describe, and this observation was made without a specific search. More significantly, one of the suspects, who was kept under 3-monthly observation because of wide physiological cups and tensions between $\mathrm{I} 7$ and $27 \mathrm{~mm} . \mathrm{Hg}$ (Schiötz) without any scotoma found on ordinary search on the Bjerrum screen, suddenly presented 2 years later with a tiny haemorrhage on the edge of the right disc (Fig. 4), obvious glaucomatous changes in both discs with slight marginal choroidal recession, and recently developed scotoma (Fig. 5). Also, two of the three who had originally shown haemorrhage on one disc subsequently developed a tiny haemorrhage on the other disc with an apparent increase of scotoma in one and of cupping in both. In these two cases the ocular tension was well controlled. One was considered to be a low-tension type and in both cases vascular insufficiency was thought to be the major defect. It appears to me that these haemorrhages, when they do occur, indicate a definite deterioration from an extra nerve fibre bundle succumbing to ischaemia. 


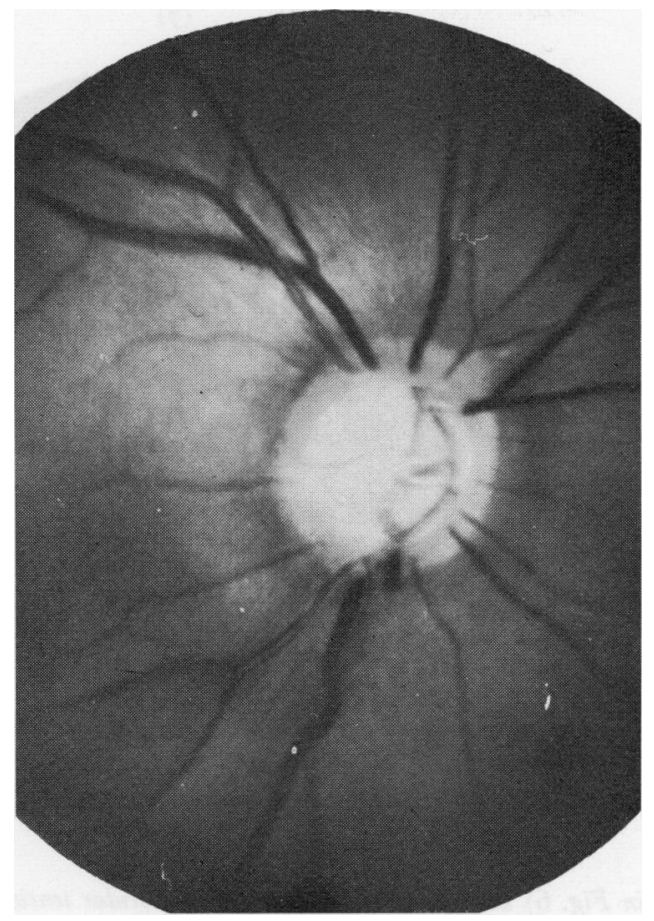

FIG. 4. A woman aged 56 yrs with glaucoma simplex had been under observation for 2 years because of wide physiological cupping. In August, 1970, a small sector haemorrhage appeared at the lower edge of the right disc and the left disc had also become glaucomatous. The intraocular pressure did not rise above $27 \mathrm{~mm} . \mathrm{Hg}$ in each eye even under provocation
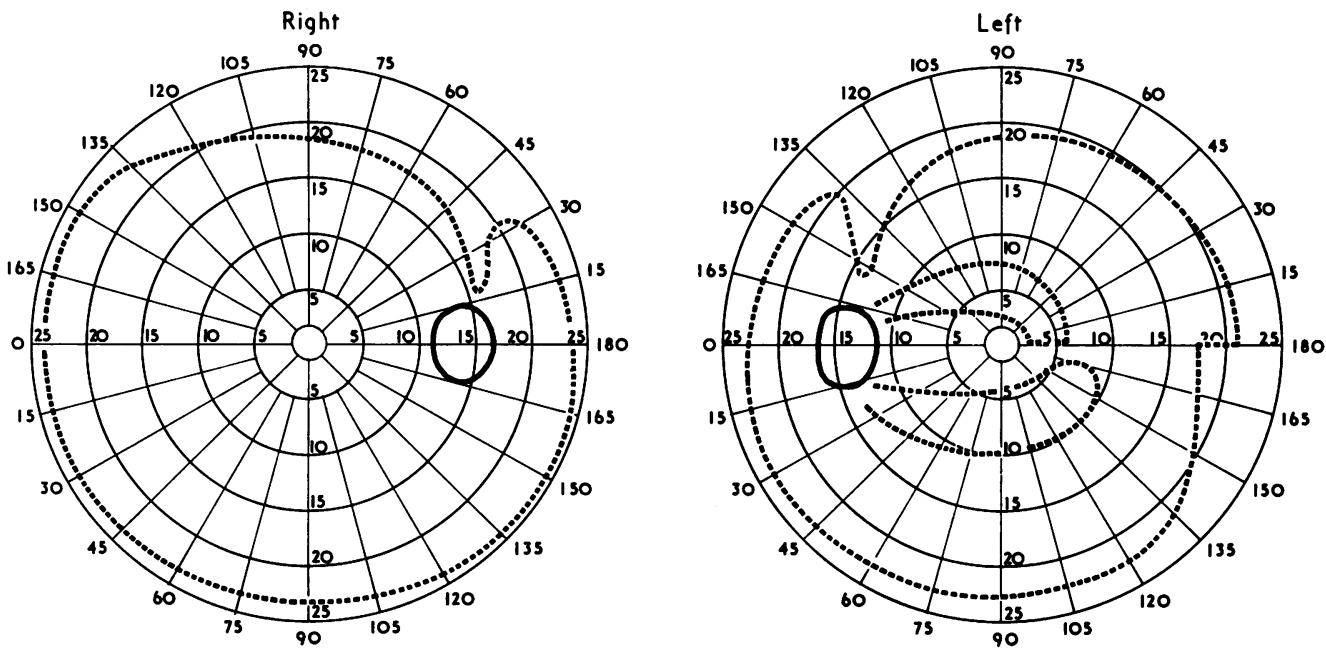

FIG. 5 Visual fields of same patient as Fig. 4, showing an early glaucomatous scotomata in the right eye and typical glaucomatous scotomata in the left. $10 / 2000$ and 2/2000 white

One feature, seen more often in narrow-angle and secondary glaucoma (Figs 6 and 7, overleaf) than in chronic simple glaucoma, is dilation of retinal vessels. There is, as shown by Dobree (1956), a reaction to a raised pressure, usually to a considerable rise, which seems to be more marked in the veins. Once the disc has become atrophic, this reactionary vasodilatation is probably not operative, as an autoregulatory mechanism such as pertains 

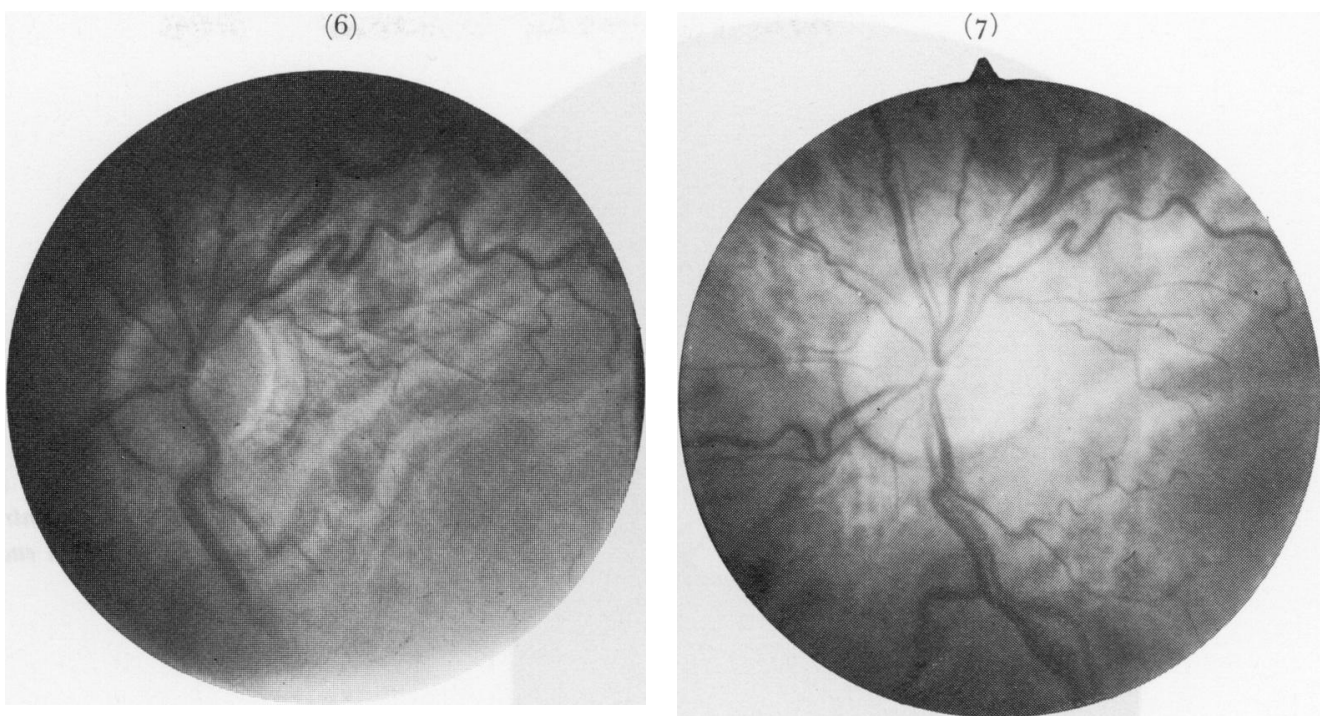

FIG. 6 A man aged $5^{8}$ yrs with subacute narrow-angle glaucoma. In February, 1968, the left fundus showed gross congestion of retinal veins, a reddened disc but no oedema, and slight peripapillary atrophy. There was an 18-mth history of " misty" attacks. When the photograph was taken the intraocular pressure was $69 \mathrm{~mm} . \mathrm{Hg}$ (Schiötz)

FIG. 7 Left fundus (of same patient as in Fig. 6) in September, 1970, after the ocular tension had been normalized by a drainage operation I year previously. All congestion has gone but there are residual peripapillaryo changes

to the retina would be dependent on active metabolism. Also, the rise in pressure seen in? the vasodilated case is seldom reached in glaucoma simplex. With chronicity, permanently dilated loops may remain around the edge of the disc (Figs 8 and 9), even when all congestion has subsided with normalization of tension or the onset of atrophy. These dilated loops may sometimes, of course, be anastomotic, overcoming some element of venous thrombosis with which glaucoma simplex may sometimes be associated.

\section{Summary}

The incidence is given of glaucoma simplex discovered by routine examination of the optic discs of all new patients over 40 years of age for the year 1968 .

The peripapillary halo was present in more than half, often quite early in the disease, and was also present in many fellow eyes as yet free from cupping.

Most of the remaining cases showed sectors of choroidal atrophy merging with the edge of the disc, and only three out of 52 cases showed no juxtapapillary signs. This choroidal atrophy is thought to be another manifestation of the susceptibility of the intraocular tissues supplied by the circle of Zinn to raised intraocular pressure (the other susceptible tissue being that of the disc itself).

Sector haemorrhage was seen in three cases at their initial assessment and in one further case (watched for 2 years with suspicious discs) wherein it coincided with the development of glaucomatous change.

Dilated retinal veins, thought to be an autoregulative reaction to high pressure, and venous loops on the disc without any definite sign of thrombosis, are also described in cases of glaucoma of various types. 

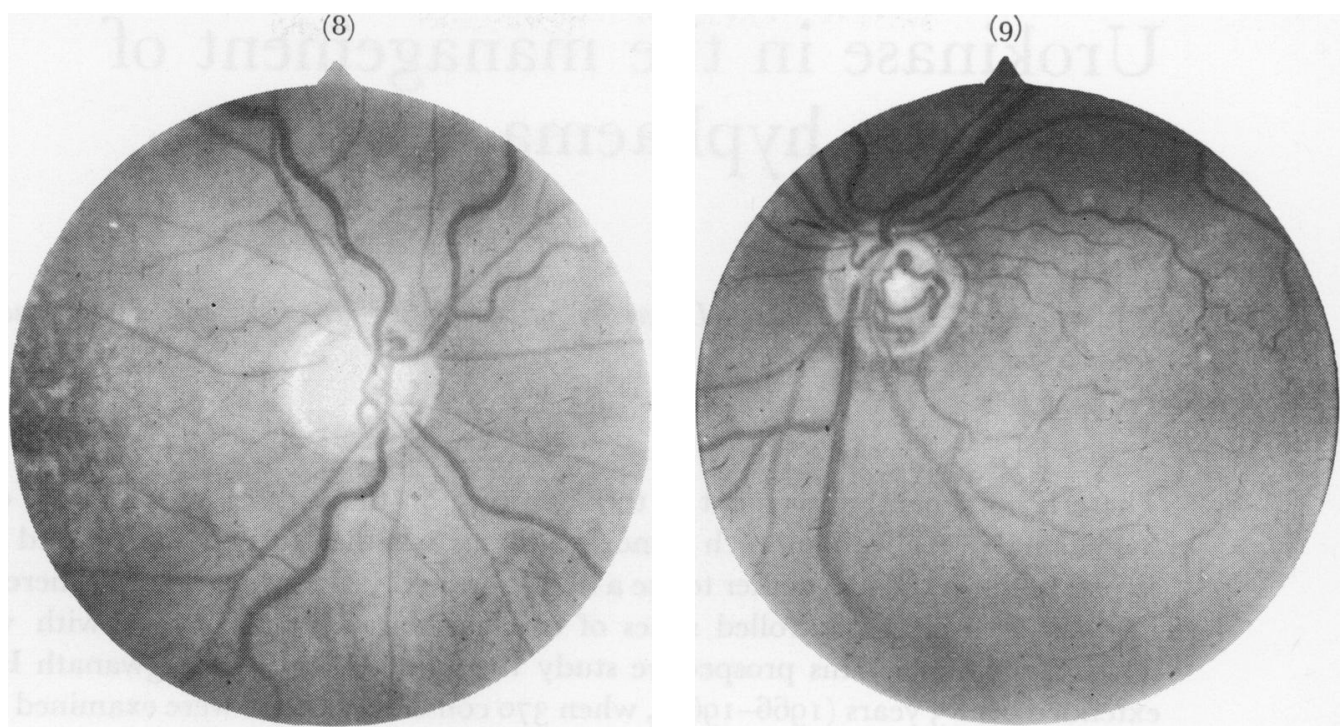

FI G. 8 A man aged 74 yrs with pigmentary glaucoma. In November, 1970, the right fundus showed congested veins with venous looping at nasal edge and moderate glaucomatous cupping with narrow sector of edging on temporal side. Intraocular pressure, $36 \mathrm{~mm} . \mathrm{Hg}$ (Schiötz) in the right eye and $24 \mathrm{~mm} . \mathrm{Hg}$ in the left, subsequently rose to $39 \mathrm{~mm} . \mathrm{Hg}$ in both eyes. Trephine operations were performed in February, $197 \mathrm{I}$

FIG. $9 A$ man aged 72 years with glaucoma simplex. In August, 1969, the left fundus showed congested veins with extensive venous looping at the base of a moderate glaucomatous cup. There was no sign of thrombosis. The right eye also showed congested veins but no loops. The intraocular pressure was $36 \mathrm{~mm} . \mathrm{Hg}$ (Schiötz) in the right eye and $3 \mathrm{I} \mathrm{mm} . \mathrm{Hg}$ in the left

\section{References}

Ballantyne, A. J., and michaelson, i. c. (1962) "Textbook of the Fundus of the Eye". Livingstone, Edinburgh and London

BOYD, T. A. S., and ROSEN, E. s. (1970) Canad. J. Ophthal., 5, 12

DOBREE, J. H. (1956) Brit. J. Ophthal., 40, I

DRANCE, S. M., and BEGG, I. s. (1970) Canad. F. Ophthal., 5, I37

GAFNER, F., and GoldmanN, H. (1955) Ophthalmologica (Basel), 130, 357

HAYREH, s. S. (1969) Brit. F. Ophthal., 53, 72 I

and Walker, w. м. (1967) Amer. F. Ophthal., 63, 982

PRIMrose, J. (1969) Trans. ophthal. Soc. U.K., 89, 585 